\title{
Exploring different choices of "time zero" in the autogenous shrinkage deformation of cement pastes containing superabsorbent polymers
}

\author{
José Roberto Tenório Filho ${ }^{1}$; Maria Adelaide Pereira Gomes de Araújo²; Didier \\ Snoeck $^{3}$; Els Mannekens ${ }^{4}$; Nele De Belie ${ }^{5}$
}

1,2,3,5 Magnel Laboratory for Concrete Research, Department of Structural Engineering, Faculty of Engineering and Architecture, Ghent University, Technologiepark Zwijnaarde 60, B-9052 Ghent, Belgium; email: 'joseroberto.tenoriofilho@ugent.be, 22adelaide.araujo@ugent.be, ${ }^{3}$ didier.snoeck@ugent.be, ${ }^{5}$ nele.debelie@ugent.be

${ }^{1}$ SIM vzw, Technologiepark 48, Zwijnaarde B-9052 Ghent, Belgium.

${ }^{2}$ Polymer Chemistry and Biomaterials Group, Department of Organic and Macromolecular Chemistry, Ghent University, Ghent, Belgium.

${ }^{4}$ Chemstream bvba, Drie Eikenstraat 661, 2650 Edegem, Belgium; email: els.mannekens@chemstream.be

\begin{abstract}
Shrinkage in concrete structures has been the focus of many studies. Lately a lot of attention has been given to autogenous shrinkage. Although it may not be prominent in ordinary concrete structures, in systems with very low water-to-cement/binder ratio (ultra-high performance concrete for example) it can become a serious issue associated with the cracking of the structure at early age. This type of shrinkage develops due to a reduction in the internal relative humidity of the material and it is also associated to the development of capillary pressure in the pore system due to receding menisci. A big challenge in studying autogenous shrinkage is determining the "time-zero". Given a lack of consensus in literature, this study aimed to investigate the influence of different estimations of time-zero: the final setting time determined by both an electronic Vicat apparatus and ultrasonic measurements; the "knee-point" in the shrinkage curve; and the capillary pressure build-up. Cement pastes with and without superabsorbent polymers (SAPs) were produced with Portland cement CEM III-B 42.5 $\mathrm{N}$ and superplasticizer (Glenium 51,35\% conc.). SAPs have proven to be quite effective in the mitigation of autogenous shrinkage as they can act as water reservoirs for the system. Among all methods, the capillary pressure was very suitable for all mixtures. For those containing SAPs no difference was found in picking the time-zero with any method. For the one without SAPs and lower w/c the choice of time-zero based on the setting time led to a different magnitude of autogenous shrinkage deformation in comparison to the other methods, which could be interpreted as an underestimation of the autogenous shrinkage deformation.
\end{abstract}

Keywords: autogenous shrinkage; time-zero; hydrogels; superabsorbent polymers. 


\section{INTRODUCTION}

In cementitious materials after contact of water with cement and during hydration, many changes take place in the material structure. From that moment until the cementitious material reaches its final setting chemical and physical processes result in expansion and shrinkage that can initiate cracking in the hardening material. Shrinkage in concrete structures has been the focus of many studies, and lately a lot of attention has been given to autogenous shrinkage. Although the autogenous shrinkage may not be prominent in ordinary concrete structures, in systems with very low water-tocement/binder ratio (ultra-high performance concrete for example) (lower than 0.42 (JENSEN \& HANSEN, 2001)) it can become a serious issue associated with the cracking of the structure at early age.

This type of shrinkage is known to be related to a reduction in the internal relative humidity of the material (consequence of chemical shrinkage) and associated to the development of capillary pressure in the pore system due to receding menisci (LURA, 2003; BENTZ \& JENSEN, 2004; JENSEN \& HANSEN, 2001). The use of internal curing agents has proven to be quite effective in the mitigation of this kind of shrinkage and special attention has been given to the use of hydrogels as they can act as water reservoirs for the system, keeping its levels of internal relative humidity high for a considerable time frame (SNOECK, 2015; MECHTCHERINE et al., 2009; JENSEN, 2008).

One of the main challenges in the study of the autogenous shrinkage in cementitious materials is the determination of time-zero. Some authors refer to it as the time when the material presents a skeleton structure that can transfer the tensile stresses along the material and suggest the final setting time as the time-zero (HAMMER and BJØNTEGAARD, 2006). Others consider it as the moment when there is a drop in the internal relative humidity of the material. The drop in relative humidity associated to the self-desiccation results in an increase in the capillary pressure, which was studied by Miao et al. (2007) as an indication for the time-zero. Darquennes et al. (2011) pointed out that the moment of change in the curvature of the shrinkage curve (a kneepoint) could indicate the point from which the chemical shrinkage is no longer capable of promoting relevant changes in the volume of the material given the existence of solid skeleton restraining such deformations and for that could also be considered as a logical choice for the time-zero.

This study was based on a comparison of the deformation due to autogenous shrinkage in cement pastes with and without superabsorbent polymers as internal curing agents. Given the lack of consensus in literature, the time-zero was taken as the final setting time determined by both an electronic Vicat apparatus and ultrasonic measurements; the so-called "knee-point" observed in the shrinkage deformation curve of the pastes; and by the build-up in the capillary pressure. 


\section{MATERIALS AND METHODS}

\section{Mixture compositions}

All tests were performed on cement pastes produced with cement type CEM III-B $42.5 \mathrm{~N}-\mathrm{LH} / \mathrm{SR}$; a polycarboxylate superplasticizer (at a constant dosage of $0.3 \mathrm{~m} \%$ in relation to the cement mass; Glenium 51, 35\% conc.); and two superabsorbent polymers hereby identified as SAP1 and SAP2.

SAP1, provided by BASF, is a copolymer of acrylamide and sodium acrylate produced by bulk polymerization and subsequently ground to a mean particle size ( $\mathrm{D}_{50}$ ) of $40 \mu \mathrm{m}$ and absorption capacity of $27 \mathrm{~g}$ of water per $\mathrm{g}$ of SAP in cement paste. SAP2, produced by ChemStream, consists of the co-monomer NaAMPS (2-acrylamido-2-methyl-1propanesulfonic acid sodium salt), diluted with a non-charged or neutral monomer ACMO (acryloyl morpholino acrylate), and has a mean particle size $\left(\mathrm{D}_{50}\right)$ of $100 \mu \mathrm{m}$ and absorption capacity of $50 \mathrm{~g}$ of water per $\mathrm{g}$ of SAP in cement paste. In both cases the absorption capacity was measured by means of comparing flow table values (EN 1015-3 (CEN, 1999) 10 min after the first contact of the dry SAPs with water in the paste. Information on the composition of the pastes can be found in Table 1 . The mixing procedure adopted for all the mixtures followed the standard NBN EN 196-1 with the superplasticizer added after the water.

Table 1. Composition of the cement pastes

\begin{tabular}{lcccc}
\hline Mixture & Effective w/c & Total w/c & $\begin{array}{c}\text { Amount of } \\
\text { SAPs [m\%] }\end{array}$ & $\begin{array}{c}\text { Amount of } \\
\text { superplasticizer } \\
{[\mathbf{m} \%]^{\mathbf{1}}}\end{array}$ \\
\hline REF0.30 & 0.3 & 0.3 & 0 & 0.3 \\
REF0.354 & 0.354 & 0.354 & 0 & 0.3 \\
SAP1 & 0.3 & 0.354 & 0.2 & 0.3 \\
SAP2 & 0.3 & 0.4 & 0.2 & 0.3 \\
\hline
\end{tabular}

${ }^{1} \mathrm{~m} \%$ versus cement

The $0.30 \mathrm{w} / \mathrm{c}$ ratio was chosen, as this REF mixture would show pronounced autogenous shrinkage. The second reference, REF0.354 was included based on the theory of Powers and Brownyard (1948) which was adapted by Jansen and Hansen (2001) for the case of internal curing. According to their study, and additional amount of water corresponding to $\mathrm{w} / \mathrm{c}=0.054$ stored in the SAPs is enough for an effective internal curing in mixtures produced with ordinary Portland cement. The mixtures with SAP1 and SAP2 contain the minimum amount of SAP and additional water that was found to effectively mitigate the autogenous shrinkage.

The experimental program was based on the measurement of the autogenous shrinkage deformation of the mixtures; the hardening of the mixtures studied by means of Vicat test and ultrasonic pulse velocity (UPV); the build-up in the capillary pressure. 


\section{Measuring the autogenous shrinkage}

The autogenous shrinkage was assessed according to the standard ASTM C1698-09. The test consists of the measurement of the deformation of specimens in corrugated tubes with a nominal length of $425 \pm 5 \mathrm{~mm}$ and a diameter of $29 \pm 0.5 \mathrm{~mm}$. The specimens were placed on metallic supports with one linear variable differential transducer (LVDT) with a range of $5 \mathrm{~mm}$ on one end. The other end was restrained in movement. The measurements were performed continuously every $10 \mathrm{~min}$ for 7 days in a room with controlled humidity $(60 \pm 5 \%)$ and temperature $\left(20 \pm 1{ }^{\circ} \mathrm{C}\right)$. The kneepoint in the curve was determined as the point with a (local) absolute maximum value of strain in time, immediately followed by a reduction in the strain values. After this point a change in the deformation rate was observed for all mixtures, thus being considered as the point of solid-fluid transition.

\section{The hardening of the mixtures}

The final setting time of the mixtures was studied by means of an electronic Vicat apparatus in compliance with EN 196-3. The UPV was determined with a FreshCon equipment (REINHARDT \& GROSSE, 2004) using compressive pulse waves. The measurements were automatically performed each five minutes during 48 hours with an amplifying voltage of $450 \mathrm{~V}$. The final setting time was then approximately determined based on the first derivative of the wave velocity in time. The maximum value of the derivative was chosen, representing the point where the rate of increase in the wave velocity switches to a slower pace.

\section{The build-up in the capillary pressure}

A small pressure transducer (RVAP015GU, Sensortronics) monitored the development of the capillary pressure, from the voltage variation due to the water flow, every $10 \mathrm{~min}$ for 24 hours. The test apparatus (Figure 1) consists of a plastic cup (400 ml) where a plastic tube is inserted with a piece of sponge at one end and the pressure transducer on the other. Right after a continuous flow of water could be observed in the narrow plastic tube, the transducer was inserted at the outer end of the tube and the measurement of voltage was continuously recorded.

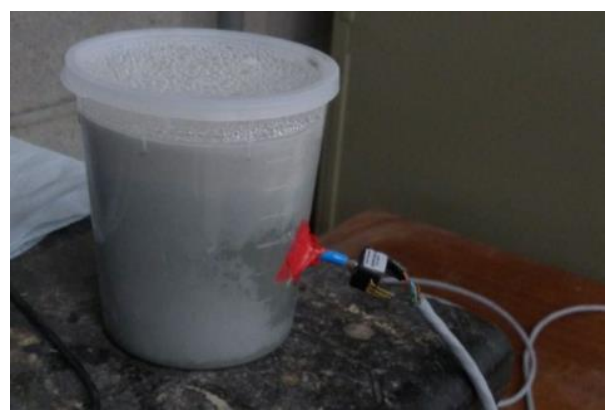

Figure 1. Set-up for capillary pressure test 


\section{RESULTS AND DISCUSSION}

From Figure 2 to Figure 5 the shrinkage strain is compared with the development of capillary pressure for each mixture. The time corresponding to the knee-point of the shrinkage curve, final setting with both Vicat and UPV is also indicated.

In the reference with a w/c of 0.30 (Figure 2) the knee-point coincides with the breakdown in the pressure and both occur first. The Vicat and the FreshCon thresholds show points very close in time but with a later occurrence in comparison with the others. The lower amount of water in the system (in comparison with all mixtures studied) causes the matrix to reach the fluid-solid transition earlier and that is immediately followed by the build-up/breakdown in the capillary pressure.

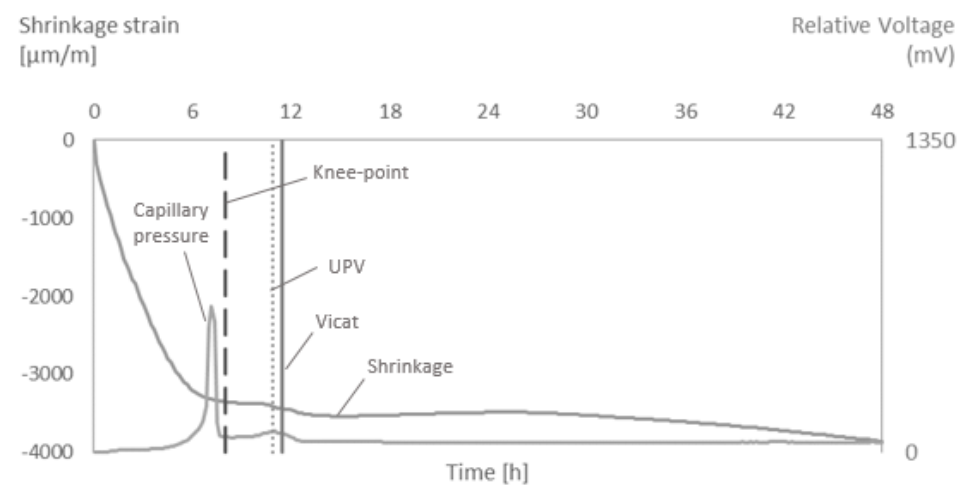

Figure 2. Shrinkage strain and development of capillary pressure for the mixture REF 0.30

In the reference with w/c of 0.354 (Figure 3) the same sequence for knee-point, FreshCon and Vicat is found. The capillary pressure shows a breakdown that is delayed in comparison to the rest but coincident with the final setting determined with the Vicat apparatus.

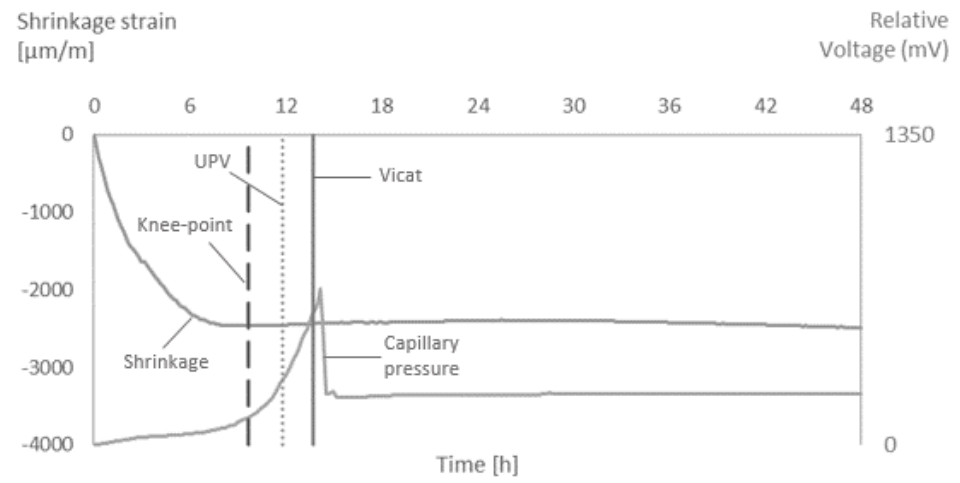

Figure 3. Shrinkage strain and development of capillary pressure for the mixture REF 0.354

Due to the higher amount of water in REF0.354 in comparison with REF0.30, the pores formed after the transition take longer to be empty so the time when the radius of the water menisci changes and the moment of breakdown in the pressure are both delayed, 
occurring around the final setting. According to Bentz and Jensen (2004), the formation of a stable solid skeleton is an essential condition for the self-desiccation, but it does not necessarily mean that this phenomenon will take place immediately after the formation of the skeleton when it comes to mixtures with w/c around or higher than 0.42 .

In the mixtures containing the SAP1 (Figure 4) and SAP2 (Figure 5), the time-zero defined by all the different methods are very close meaning that the final setting might occur right after the transition point and approximately at that moment of pressure breakdown. In relation to the action of the SAPs as internal curing agents the water of internal curing causes a delay in the moment when the pressure breakdown occurs, in relation to the reference with a $\mathrm{w} / \mathrm{c}$ of 0.3 .

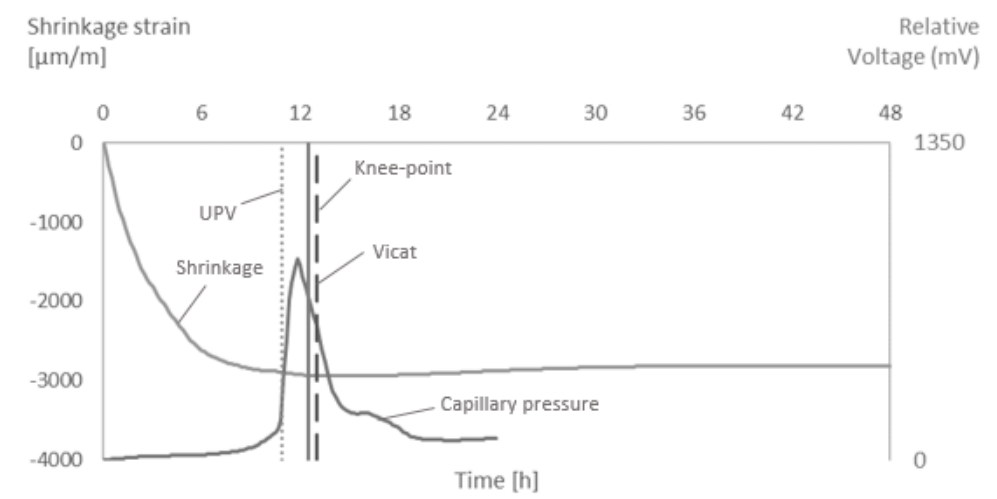

Figure 4. Shrinkage strain and development of capillary pressure for the mixture SAP1

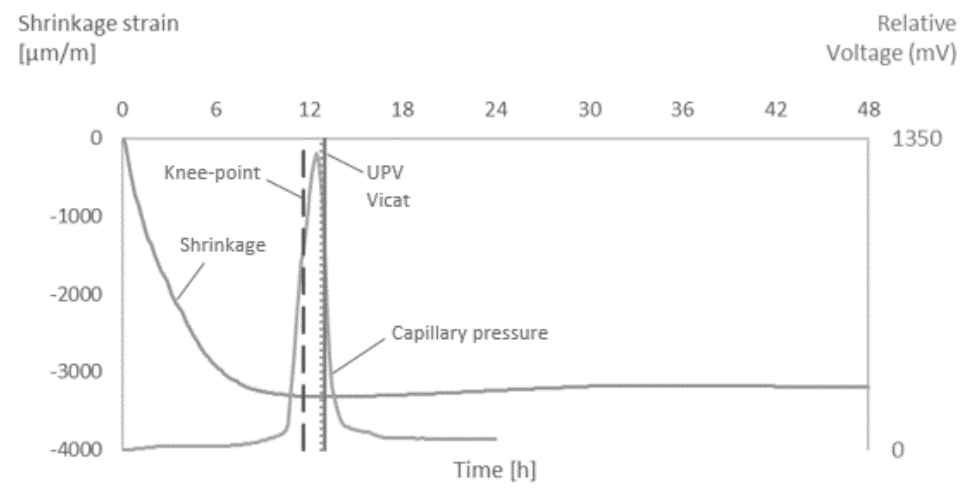

Figure 5. Shrinkage strain and development of capillary pressure for the mixture SAP2

All the mixtures with a total w/c higher than 0.3 showed a delay of about six hours in the moment for the pressure breakdown. This could also indicate a delay in the moment of crack initiation due to autogenous shrinkage. From this point of view, it might appear that the reference with w/c 0.354 is as efficient as the mixtures with SAPs in terms of controlling the self-desiccation, which is not the case and will be shown in the next part of the discussion. 
Picking the time-zero based on different methodologies can influence the correct analysis of the autogenous shrinkage depending on the composition of the mixture. Figure 6 shows the autogenous shrinkage strain of all pastes during the first seven days of age with different choices for time-zero. For the REF with a w/c of 0.3 the time when the maximum voltage was recorded in the capillary pressure test was compared to the final setting time determined by the Vicat. For REF0.354 the knee-point versus the maximum voltage was plotted. Given the proximity of the results in the mixtures with SAPs only the moment of maximum voltage was chosen.

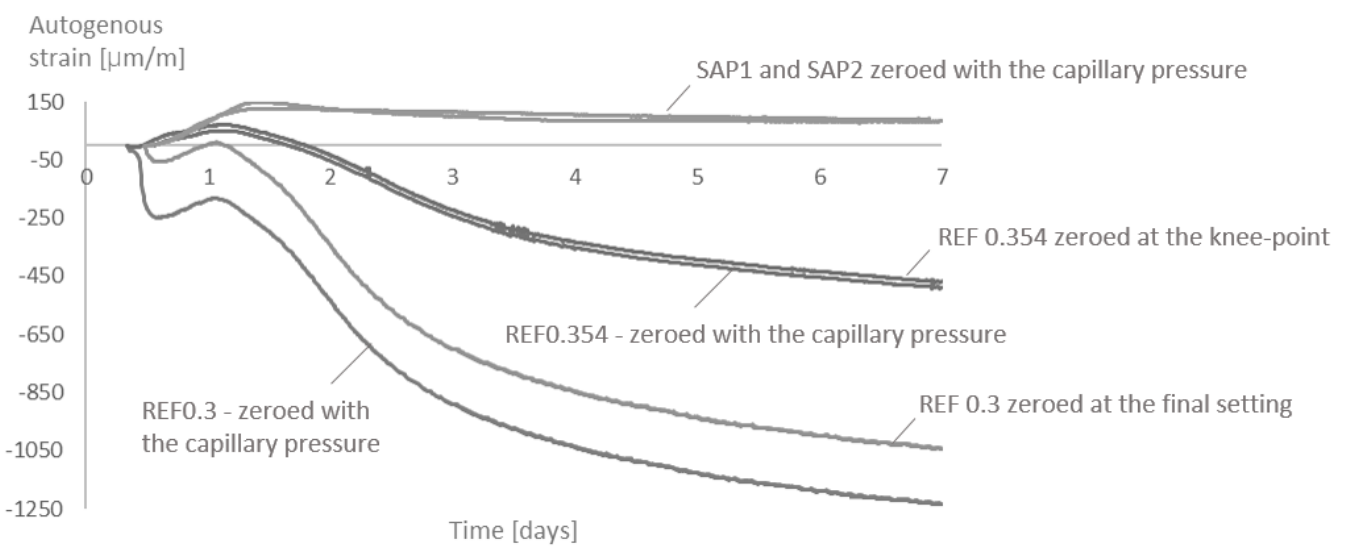

Figure 6. Autogenous deformation for all mixtures with different zero-times

In the REF0.3 the choice of time-zero based on the final setting would lead to an underestimation of the autogenous shrinkage strain with a difference around $200 \mu \mathrm{m} / \mathrm{m}$. Regarding the REF0.354 even though a difference in time was obtained between the occurrence of the knee-point and the breakdown of pressure, no significant difference was found in the autogenous shrinkage strain. The same can be extended to the mixtures with SAPs, where all the test methods tend to converge to a same point in time.

\section{CONCLUSION}

The build-up of capillary pressure is a phenomenon that has been already associated to the autogenous shrinkage in cementitious materials. The results in this paper showed it can be quite precise in estimating the time-zero, following the theories connecting it to the self-desiccation, and with a good correspondence with other existing methods and definitions, especially the knee-point in the shrinkage strain curve.

The knee-point could be used as a good approximation for the time-zero in the mixtures with lower w/c and those containing SAPs. Adopting this method could save time and material since it does not require extra tests besides the already needed measurement of autogenous shrinkage. To provide further validation and wider application of the results shown in this paper a few suggestions for future investigation can be given: other kinds of cement and w/c should be tested; test different types of SAPs to verify a 
possible influence of their chemistry composition in terms of mitigating autogenous shrinkage.

\section{ACKNOWLEDGMENTS}

The work has been financed by SIM program SHE (Engineered Self-Healing Materials) within the ICON project iSAP (Innovative SuperAbsorbent Polymers for crack mitigation and increased service life of concrete structures).

\section{REFERENCES}

BENTZ, D. P., JENSEN, O.M. Mitigation strategies for autogenous shrinkage cracking. Cem. Concr. Compos. 26 (2004) 677-685.

DARQUENNES, A., STAQUET, S., DELPLANCKE-OGLETREE, M., ESPION, B. Effect of autogenous deformation on the cracking risk of slag cement concretes. Cem. Concr. Compos. 33 (2011) 368-379.

HAMMER, T. A. AND BJØNTEGAARD, Ø. Testing of autogenous deformation $(A D)$ and thermal dilation (TD) of early age mortar and concreteRecommended test procedure. Proc. Int. RILEM Conference on volume changes of hardening concrete: testing and mitigation, Lyngby, Denmark, pp. 341-346. 2006.

JENSEN, O.M., HANSEN P.F. Autogenous deformation and RH-change in perspective. Cem. Concr. Res. 31 (12) (2001) 1859-1865.

JENSEN, O.M. Use of superabsorbent polymers in construction materials. International Conference on Microstructure Related Durability of Cementitious Composites, Nanjing, 757-764. 2008.

LURA, P. Autogenous Deformation and Internal Curing of Concrete. PhD thesis Delft University of Technology, the Netherlands, 200315.

MECHTCHERINE, V., DUDZIAK, L., \& HEMPEL, S. Mitigating early age shrinkage of Ultra-High-Performance Concrete by using Super Absorbent Polymers (SAP). Paper presented at the Creep, Shrinkage and Durability Mechanics of Concrete and Concrete Structures, Ise-Shima, Taylor \& Francis, 847-853. 2009.

MIAO, C.-W., QIAN, T., WEI, S. AND JIA-PING, L. Water consumption of the early-age paste and the determination of "time-zero" of self-desiccation shrinkage. Cement and concrete research, 37(11), pp.1496-1501. 2007.

POWERS, T.C., BROWNYARD, T.L. Studies of the physical properties of hardened Portland cement paste (Vol. 22). Cornell: Portland Cement Association, Research Laboratories, pp. 892. 1948.

REINHARDT, H.W., \& GROSSE, C.U. (2004). Continuous monitoring of setting and hardening of mortar and concrete. Construction and Building Materials, 18(3), 145-154.

SNOECK, D. Self-Healing and Microstructure of Cementitious Materials with Microfibres and Superabsorbent Polymers. Doctorate thesis - Faculty of Architecture and Engineering/Ghent University. Belgium, 2015. 